\title{
Pitfalls of Social Media
}

\author{
Daniel Sassoon, PhD, Richard B. Gunderman, MD, PhD \\ Indiana University School of Medicine, Indianapolis, Indiana
}

Popularized in the 1990s, the term social media has come to refer to a variety of Internet-based tools for sharing ideas and impressions. Today some of the more popular services are Facebook, Pinterest, Twitter, and YouTube, each of which has registered users numbering in the hundreds of millions or even billions. Social media have drawn viewers and revenue away from traditional media, such as newspapers, magazines, radio and television stations, and recorded media including CDs and DVDs. Although social media's allures are obvious to many users, three of their particularly important pitfalls for radiologists may be less clear.

One major pitfall of social media is their velocity. Broadcast media shortened the news-response time from days to hours, and social media have reduced it further to minutes. To stay on top of such a fast-paced cycle, users who aspire to influence need to post quickly and frequently. Seeing something of potential interest, they feel compelled to share it immediately, before someone else beats them to the punch. As a result, knee-jerk and off-the-cuff responses tend to rule the day. The downside, of course, is often a race to the bottom in terms of the depth and quality of insight such posts offer. Too often, attention shifts elsewhere before a thoughtful perspective can take shape.

Another pitfall is the sensationalization and polarization of the points of view expressed. Because one of the principal aims of many serious users is to create a following, there is an ever-present incentive to express strong views, especially anger. Moderation and balance tend not to be as richly rewarded in this domain, and there are fewer checks on the expression of extreme and even antagonistic points of

This is the author's manuscript of the article published in final edited form as:

Sassoon, D., \& Gunderman, R. B. (2018). Pitfalls of Social Media. Journal of the American College of Radiology, 15(2), 371. https://doi.org/10.1016/j.jacr.2017.08.025 
view. This reflects the fact that most users operate from a perch of privacy, interacting only with a digital device and never meeting their targets face to face. When there is insufficient time to examine issues in depth, outrage tends to dominate the day.

Perhaps the most serious pitfall of social media is their tendency to draw attention away from deeper, better articulated, and more balanced sources of insight. Every minute a user spends monitoring Facebook or Twitter is a minute lost to some other form of exploration and learning, such as reading a journal or a good book. Sophocles, Shakespeare, and Tolstoy did not write in 140-character posts, and it is quite possible that what they had to say could not be conveyed in such a form. In fact, the problem is direr than that because over time a mind nurtured and sustained primarily on social media may lose interest in engaging serious works of thought and art.

The point is not that radiologists should entirely eschew social media. After all, services such as Pinterest and YouTube can serve to draw attention to and share truly worthy content. But discretion is called for. For example, we have attended professional meetings lately where Twitter feeds are running across the bottom of projection screens, distracting attendees from the speakers' message with an endless series of retweets. Moderation is also called for. Instead of checking email several times per hour, most radiologists would do better to check it daily. Each time attention switches to social media, it takes additional time and energy to reorient to the primary task at hand.

Social media have their place, but it is a limited place, and one whose limits some colleagues are increasingly struggling to abide by. Too often, social media are functioning less to engross us and more to distract us from the things that are truly worth attending to. In an age when more and more demands are being placed on the time of radiologists, it is more urgent than ever that we discern clearly the activities that are truly most worthwhile. Social media can entertain, provoke, and even inform us. But when it comes to fostering our most important professional resources—-wisdom, compassion, and dedication— they too often have too little to offer. 